\title{
Primary Outcome Variable
}

National Cancer Institute

\section{Source}

National Cancer Institute. Primary Outcome Variable. NCI Thesaurus. Code C142644.

The study outcome factor of greatest priority that contributes to the main objective of the trial. 